Gastón Espinosa, Virgilio Elizondo, Jesse Miranda, (eds.), Latino Religions and Civic Activism in the United States

New York, Oxford University Press, 2005, 350 p.

Ronan Teyssier

URL : http://journals.openedition.org/assr/15293

DOI : $10.4000 /$ assr. 15293

ISSN : $1777-5825$

Éditeur

Éditions de l'EHESS

Édition imprimée

Date de publication : 1 juin 2008

Pagination : 191-321

ISBN : 978-2-7132-2190-3

ISSN : 0335-5985

Référence électronique

Ronan Teyssier, «Gastón Espinosa, Virgilio Elizondo, Jesse Miranda, (eds.), Latino Religions and Civic Activism in the United States », Archives de sciences sociales des religions [En ligne], 142 I avril-juin 2008 document 142-26, mis en ligne le 25 novembre 2008, consulté le 21 septembre 2020. URL : http:// journals.openedition.org/assr/15293; DOI : https://doi.org/10.4000/assr.15293 


\section{Gastón Espinosa, Virgilio Elizondo, Jesse Miranda, (eds.), Latino Religions and Civic Activism in the United States}

New York, Oxford University Press, 2005, 350 p.

\section{Ronan Teyssier}

1 Si l'on ne compte plus les travaux empiriques qui documentent, depuis une quinzaine d'années aux États-Unis, l'impact du facteur religieux sur le «capital social» et la "participation communautaire, politique, sociale ou encore civique», on ne manque pas en revanche de constater la relative absence des communautés américaines d'origine mexicaine, centre-américaine ou latino-américaine dans ces études. C'est précisément à cette lacune que l'ouvrage dirigé par G. Espinosa, V. Elizondo et J. Miranda vise à remédier en présentant une quinzaine d'études de cas sur l'engagement social individuel et collectif de catholiques et de protestants hispanoaméricains.

2 L'objectif assigné à cet ouvrage est double. Il s'agit d'une part de documenter l'impact de la religion sur l'implication sociale d'individus et de groupes au sein de diverses communautés hispano-américaines. Cela passe à la fois par une analyse historique et une analyse plus sociologique de situations contemporaines. Ce livre est présenté d'autre part comme étant la base descriptive et contextuelle d'un second ouvrage portant sur le même thème mais dont la méthode reposera sur l'analyse des enquêtes quantitatives du projet Hispanic Churches in American Public Life (p. 5).

G. Espinosa, V. Elizondo et J. Miranda ont choisi de classer les textes en deux parties, l'une traitant historiquement de l'impact de la religion sur l'activisme social dans les communautés hispano-américaines, l'autre abordant ce thème à la lumière d'expériences actuelles (p. 6). Plusieurs contributions donnent toutefois le sentiment que la frontière entre le passé et le présent est loin d'être clairement marquée rendant l'organisation des chapitres quelque peu artificielle.

4 Le premier chapitre offre une entrée en matière large et ambitieuse traitant de l'impact des pratiques traditionnelles catholiques mexicaines sur la résistance à la Conquête 
américaine dans la seconde moitié du XIX ${ }^{\mathrm{e}}$ siècle. Dans la mesure où les chapitres de ce livre sont relativement courts, et que cette contribution n'y fait pas exception, c'est un tableau à grands traits qui est tiré.

Les trois chapitres suivants entrent plus spécifiquement dans le sujet et ont en commun de traiter de personnages importants dans l'histoire de l'activisme social et politique hispano-américain. Les chapitres 2 et 3 s'intéressent à César Chávez, le plus célèbre syndicaliste et activiste des droits civiques hispano-américain. Ces deux contributions sont à la fois originales et instructives. La première d'entre elle porte un éclairage nouveau sur le mysticisme de Chávez (manifesté par exemple dans ses jeûnes) envisagé comme étant le moteur de son activisme social (p.37). Ce faisant, l'auteur accomplit deux ruptures, l'une avec les définitions du concept de «mysticisme » comme étant une attitude de détachement par rapport aux enjeux sociaux immédiats et l'autre, plus empirique, avec les biographes de Chávez, qui minorent la centralité de la croyance et de la pratique religieuses catholiques dans l'engagement de ce dernier. Le chapitre 3 envisage quant à lui Chavez sur le mode d'une allégorie de la Passion du Christ (pp. 55-56) mais du point de vue de l'impact de la religion sur l'activisme social. Le chapitre 4 est plus intéressant. En effet, il y est principalement question de la biographie de Reies López Tijerina, autre activiste hispano-américain célèbre. Le chapitre se termine par une excellente discussion comparative de la "réussite " respective de Tijerina et Chávez par référence à leur adéquation avec la religion civile américaine entendue dans la perspective de Bellah (pp. 71-73).

6 Les chapitres 5, 6 et 7 abandonnent l'étude des leaders charismatiques pour envisager des groupes religieux activement engagés dans les débats sociaux des années 1960 et 1970. Sont ainsi présentés PADRES, un groupe de prêtres fondé en 1969 avec pour objectif de faire entendre une voix mexicano-américaine dans l'Église catholique américaine (p. 82) et Las Hermanas, un mouvement fondé deux ans plus tard par des nonnes et des laïques mexicano-américaines. La longue collaboration de ces deux organisations a abouti à la création d'" un centre pastoral hispanique ", le Mexican American Cultural Center dont l'histoire est présentée en détail (p. 114).

7 Le chapitre 8 est la première contribution de l'ouvrage qui traite de l'engagement social, politique et civique des protestants hispano-américains. Il y est plus spécifiquement question de la participation souvent ignorée des Églises méthodistes hispano-américaines du Sud-Ouest des États-Unis aux « luttes » culturelles et sociales des années 1960 et 1970.

8 Les deux derniers chapitres de cette première partie du livre font plus explicitement le pont entre les mouvements historiques et les expériences actuelles d'implication sociale sur base religieuse qui sont l'objet de la seconde partie. Ainsi, le chapitre 9 décrit-il la genèse, dans les années 1970, des organisations communautaires confessionnelles hispano-américaines dans plusieurs centres urbains des États-Unis (p. 146), les "faith-based organizations", celles-là même qui font l'objet depuis une dizaine d'années de l'attention des divers niveaux de gouvernement. Le chapitre 10 fait lui aussi écho à l'actualité en envisageant les relations frontalières. Il y est question de Sanctuary, un mouvement comprenant de nombreuses Églises qui a essaimé dans les années 1980 tout le long de la frontière du côté américain pour venir en aide aux Mexicains et Latino-Américains entrés illégalement aux États-Unis (p. 163).

9 La seconde partie de l'ouvrage présente d'autres études de cas dont les thèmes reprennent les situations envisagées dans la première partie. Ainsi, le chapitre 11 
prolonge-t-il par exemple le chapitre 8 en se focalisant sur l'engagement public de congrégations protestantes hispano-américaines lorsqu'elles se trouvent immergées dans des situations d'opposition «nativiste » comme ce fut le cas lors des discussions de la célèbre proposition 187 en 1994 en Californie (p. 178).

10 Le chapitre 12 aborde l'engagement social des femmes pasteurs pentecôtistes à New York. La thèse défendue va contre l'idée commune d'un certain « repli spirituel » des groupes pentecôtistes (pp. 198-199). Si le chapitre 13 porte sur l'Église Universelle du Royaume de Dieu (EURD) à Boston, son propos vise aussi à décrire les diverses modalités de l'engagement social, et dans une certaine mesure politique aussi, d'un groupe longtemps tenu comme exclusivement concerné par les affaires spirituelles. En effet, selon l'auteur, bien que le "langage de justice sociale de l'EURD » soit distinct de celui des Églises catholique et protestantes traditionnelles, il n'en est pas moins porteur d'une certaine aspiration au changement social au-delà de son objectif immédiat de transformation individuelle (p. 221).

11 Le chapitre 14 revient sur la comparaison entre les expériences collectives hispanoaméricaines et afro-américaines d'engagement social. Il ne s'agit pas cette fois d'étudier le parcours de personnages charismatiques tels que Chávez et Martin Luther King mais de comparer le fonctionnement d'une Église catholique mexicano-américaine et celui d'une Église baptiste afro-américaine à Phoenix. Les auteurs soulignent la centralité des Églises dans l'histoire des communautés afro-américaines comme espace de liberté et d'acquisition de compétences politiques (pp. 233-234). Le chapitre se conclut sur un certain nombre de recommandations enjoignant les congrégations hispanoaméricaines à s'inspirer de l'exemple afro-américain (pp. 241-245).

12 Les chapitres 15 et 16 s'intéressent tous deux à des questions fortement médiatisées impliquant une réponse religieuse visible et œcuménique à une polémique politique. Ainsi, le chapitre 15 décrit-il comment les parties catholique et protestante de la communauté cubano-américaine de Miami se sont impliquées dans la saga entourant l'arrivée en Floride du jeune Elián González. Le chapitre 16 présente quant à lui une autre illustration de rassemblements œcuméniques, l'Ecumenical Coalition of Churches for Vieques, dont l'effort de mobilisation était tout entier tourné vers le démantèlement d'une base de la marine américaine à Vieques (Porto Rico).

13 Le dernier chapitre du livre se distingue des autres contributions en ce qu'il ne porte plus sur l'étude d'un cas précis mais présente les résultats quantitatifs de deux sondages nationaux sur l'activisme social et politique des Églises et des leaders hispano-américains (p. 281). Dans ce chapitre sont explorés plusieurs thèmes tels que les dimensions de l'engagement politique et social en fonction de l'appartenance religieuse, le positionnement différencié des Églises protestantes traditionnelles, évangéliques et catholiques hispano-américaines par rapport à plusieurs enjeux sociaux. Le chapitre se conclut d'une manière originale et résolument actuelle en explorant la constitution par les hommes et femmes politiques fédéraux de réserves de votes, d'alliances et de soutiens hispano-américains. Ce chapitre réussi à introduire l'ouvrage complémentaire annoncé dès les premières pages par G. Espinosa, V. Elizondo et J. Miranda.

14 Ce livre a de nombreuses qualités dont celle d'avoir atteint l'objectif qu'il se fixait. La concision des chapitres ne nuit pas à la profondeur du propos, la qualité des contributions est constante, la thèse d'un impact durable du facteur religieux sur l'engagement social des communautés hispano-américaines est défendue de manière 
convaincante. Les diverses études de cas décrivent plusieurs facettes de cet engagement social. Il reste donc au volume suivant à accomplir la tâche de systématiser le résultat des analyses sur cette question. 